\title{
Microstructure-Performance Relation in PMMA-Based Open-Cell Porous Materials for High Pressure Ceramic Sanitaryware Casting
}

\author{
Y. Ergün ${ }^{1}$, C. Dirier ${ }^{2}$, M. Yılmaz ${ }^{2}$, C. Tokman², M. Tanoğlu ${ }^{1}$ \\ ${ }^{1}$ İzmir Institute of Technology, ${ }^{1 *}$ Material Science and Engineering Program, \\ ${ }^{1}$ Mechanical Engineering Department, Gülbahçe Campus, 35437 Urla, İzmir, Turkey. \\ ${ }^{2}$ Ege Vitrifiye Sanitaryware Inc., İzmir, Turkey.
}

\begin{abstract}
Keywords: Porous plastic materials, Polymethyl Methacrylate, High pressure casting.
\end{abstract}
\begin{abstract}
The ceramic whiteware/sanitaryware industry is rapidly undergoing to implement highpressure casting techniques for ceramic article production. In these techniques, materials with open pore microstructure that allows drainage of water under applied pressure are needed. The polymethyl methacrylate (PMMA) based polymeric porous materials have become the most suitable type of materials for this purpose because of their short casting periods and high service lives. However, the superior service life and performance of these materials are closely related to the microstructure. In the present study, the porous materials with various compositions of the constituents in the emulsion were produced to effect the microstructure of PMMA-based materials. The variations on the pore microstructure were interrelated to the performance of the material for high-pressure sanitaryware casting. The pore morphology and water permeability of the samples was measured using optical and SEM microscopy and permeability measurement techniques, respectively. The compressive collapse stress and modulus values were determined by performing compression testing. The results showed a significant interrelation between microstructure and the performance of the PMMA-based ceramic mould materials.
\end{abstract}

\section{Introduction}

Traditionally, plaster of Paris has been used as moulding material for the shaping of ceramic articles with the slip casting technique that operates under the principle of capillarity and absorption of the water from the ceramic slip. Plaster moulds are easily shaped, operated at low pressure and relatively inexpensive. However, these materials exhibit long (1-2 hours) of casting periods and limited service life (80-100 maximum cast) due to their low wear resistance. To overcome the limitations of the plaster moulds and improve the article quality and productivity, ceramic industry is implementing high pressure casting technique that provides automation to the casting process. In this technique, materials with open pore structure in which the water is transported from the ceramic slip under an applied pressure of typically 13-15 bar [1]. The polymeric materials, especially, PMMA based porous materials become the most suitable one for this technique. Using these materials provides short casting period (5-20 min) and demolding can be done immediately. Furthermore, casting period can be adjusted by changing the slip casting pressure in the limitations of the mechanical strength of the mould material. The service life and performance of polymer mould is however closely related to the microstructure and mechanical properties of the plastic material. In recent studies, reinforcing components such as clay particles were added to the plastics to improve the mechanical performance of the molds [2-3]. In the present study, porous plastic mould materials were produced by polymerization of water in oil emulsion with various compositions of the emulsion constituents and particle sizes of the PMMA beads. The effects of changing the compositions and average particle size on the pore volume and morphology, water permeability and mechanical properties were investigated. 


\section{Experimental Procedure}

Materials. The PMMA-based porous plastics were produced by polymerization of water in oil emulsion from hardenable molding compositions containing PMMA beads (Keramische Laufen, Germany), methyl methacrylate (MMA, Degussa, Germany), initiator (Peroxid-Chemie GmbH), emulsifier (Keramische Laufen, Germany) and water. Two types of PMMA beads with average particle size of 35 and $150 \mu \mathrm{m}$ were used to produce plastic moulds. PMMA beads with a smaller diameter were plastized to assist in the absorption of methyl methacrylate monomer. Dibenzoyl peroxide was used as an initiator of the polymerization reaction. In order to provide the homogeneity and the stability of the emulsion water-soluble nonionic surfactant of ethylene oxide-propylene oxide (EO-PO) block-copolymer was used.

Preparation of plastic mould materials. The porous plastics were prepared by polymerization following the mixture of water and oil phases. The water phase contained plastized beads (about 20$30 \mathrm{wt} \%$ ) suspended in the mixture of water and surfactant. The oil phase contained coarser beads (about 15-25 wt\%), monomer of MMA (about 15-20 wt \%) and the benzoyl peroxide. These two solutions were mixed together for about 30 seconds and casted on an epoxy mould. The reaction took place in about 30 minutes and the temperature was increased from $15{ }^{0} \mathrm{C}$ to $65{ }^{0} \mathrm{C}$ due to the exothermic reaction. This process resulted in randomly distributed open-cell macropore structure with an irregular morphology. During the production of these samples, surfactant/water ratio was kept constant while their total mass within the emulsion varied between 30-40 wt \% .

Characterization. Resultant pore morphology was characterized using an optical and scanning electron microscopy (SEM) and threshold of the optical micrographs were analysed using Scion $^{\mathrm{TM}}$ image analyzer software for pore fraction determination. At least seven different images were used for each specimen to determine pore fractions. The water permeability of the samples was measured using a specially designed cylindrical permeability apparatus. The samples for this test were in the diameter of $70 \mathrm{~mm}$ and a thickness of $20 \mathrm{~mm}$. The samples were subjected to 4 bar water pressure and the volume of the water permeated per time (Q) was measured. Permeability constant $\kappa$ was calculated from the equation of Henry Darcy, which describes the flow through a porous media [3]. Compressive mechanical tests were conducted on the specimens to investigate the effects of the microstructure on the mechanical properties (compressive modulus and collapse stress) of the porous plastics. Tests were carried out using a universal testing machine (Shimadzu ${ }^{\mathrm{TM}}$, Japan). Specimens were dried for 24 hours at $35{ }^{\circ} \mathrm{C}$ prior to testing and at least 5 specimens were tested at room temperature with $1.3 \mathrm{~mm} / \mathrm{min}$ stroke speed.

\section{Results and Discussion}

Figure 1 shows the polishes surface SEM micrographs of the produced samples with various concentrations of surfactant/water ratio within the emulsion. As the total weight fractions of these constituents increased as presented through Fig. 1a to 1d, respectively, the microstructure is affected significantly. The pore size and morphology and cell connectivity was changed due to the variations of the components. As shown in Fig. 2, the percentage of the porosity increased from about 34-47\% as the amount of surfactant/water increased from 29 to $40 \mathrm{wt} \%$. The macropore structure is formed from the water particles surrounded with surfactants within the solution during the polymerization of the water in oil emulsion. As the polymerization is completed, the water phase is removed from the structure and left open-cell porosity behind. At low concentrations of the water/surfactant phase, larger isolated pores were formed as illustrated in Fig. 1a. As their concentration increases, the porosity and pore connectivity increases. Fig. 2 also shows the water permeability constant of the mentioned samples as a function of surfactant/water weight fractions. As the concentrations 
increased, the porosity and effective cell connectivity increases and therefore the permeability constant of the specimens rise from 2.5 to 4.5 .

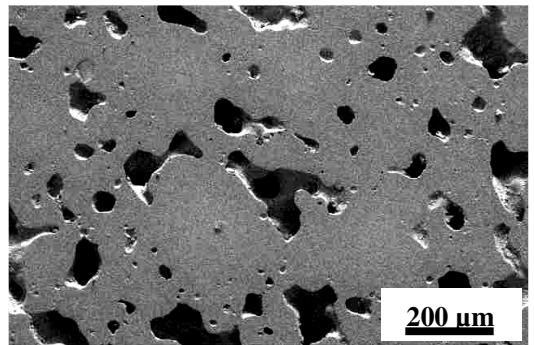

(a)

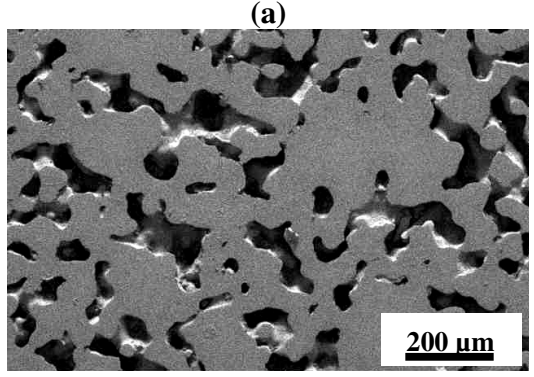

(b)

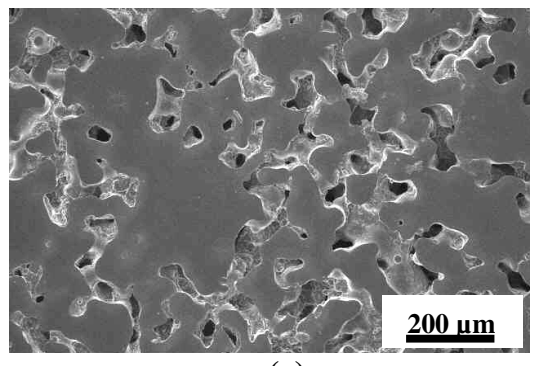

(c)

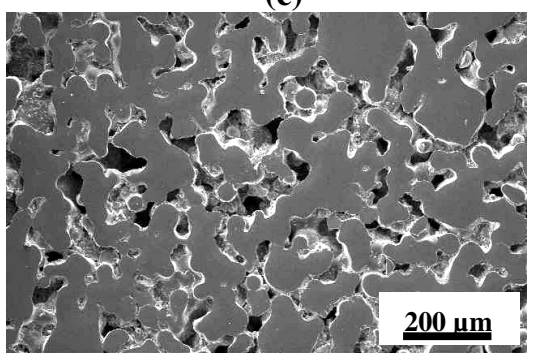

(d)

Figure 1. SEM polished surface micrographs of PMMA-based plastics, produced with various concentrations of surfactant/water. The total content of water and surfactant in the emulsions are 29 , 33, 37 and 40 for a, b, c and d, respectively.

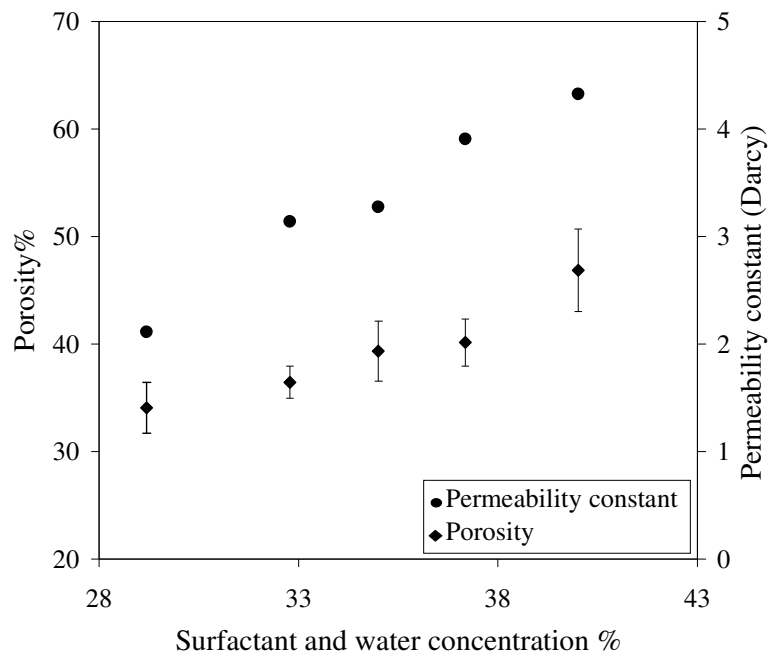

Figure 2. Porosity and water permeability constant of the PMMA-based porous plastics with respect to surfactant and water concentration.
Besides the water permeability the mechanical performance of these molding materials are critical due to applied cycled high pressure during the shaping of the ceramic articles. Fig. 3(a) shows the compressive stress-strain graphs of the samples that were produced with various water and surfactant concentrations. The results showed that the varying the concentrations and therefore the porosity affects the compressive properties significantly. From the linear elastic deformation part of the graph elastic modulus of the materials were obtained and variation of the modulus and collapse stresses with respect to concentrations was given in Fig. 3(b). There is a sharp decrease in elastic modulus and collapse stress values with increase in water/surfactant content.

In order to investigate the effects of particle size of the PMMA beads on the microstructure and performance of these materials, samples were produced with various particle diameters. Fig. 4 shows the porosity, water permeability and mechanical properties of the porous plastic samples with various particle diameter. As the PMMA particle size increases, the amount of porosity and hence the permeability values increases. However, the modulus and collapse stress values decrease significantly with increasing bead sizes. 


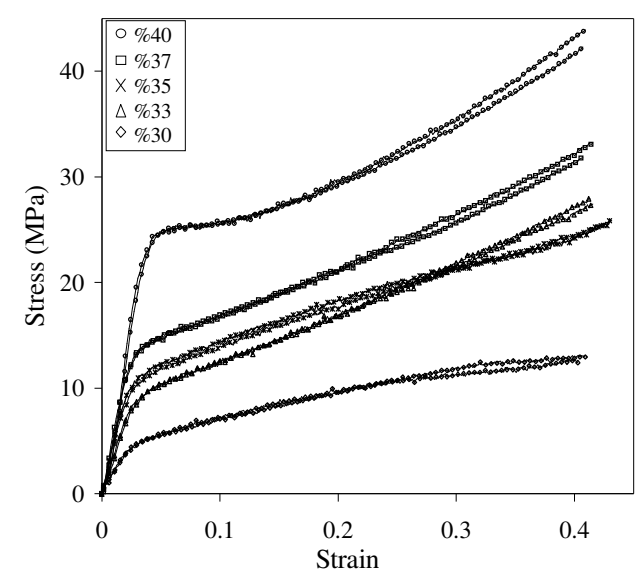

(a)

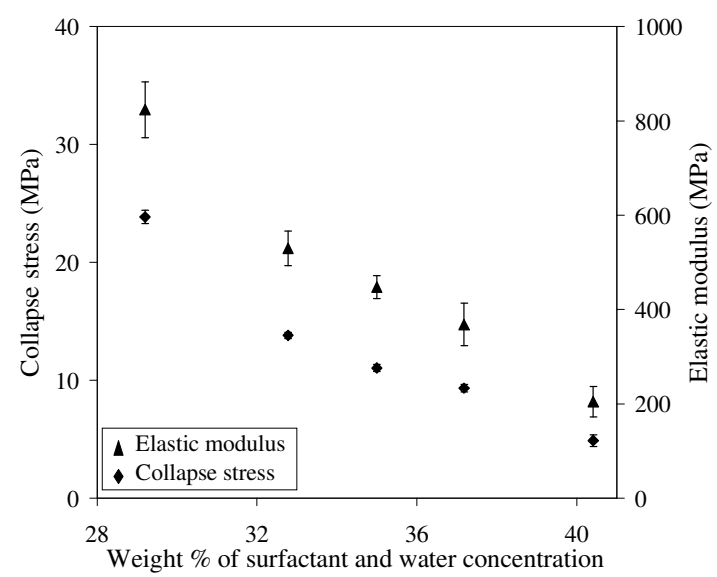

(b)

Figure 3. (a) Compression stress-strain curve and (b) variation of porosity and permeability of plastic mould samples with various surfactant and water concentration.

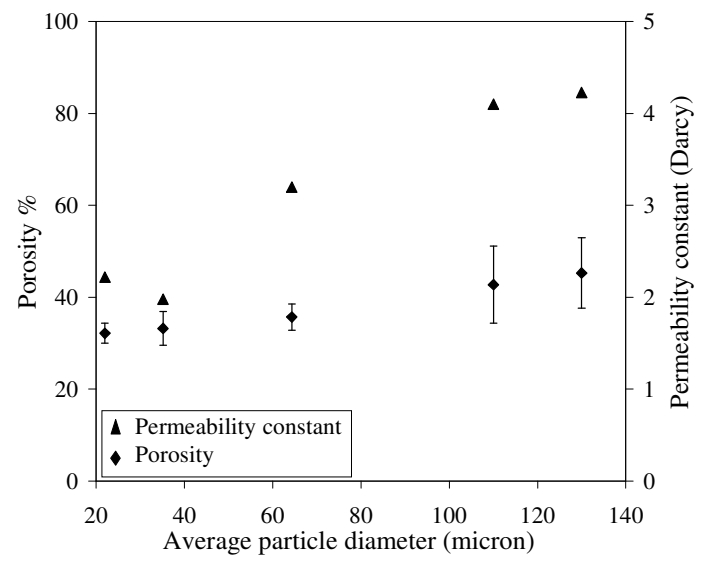

(a)

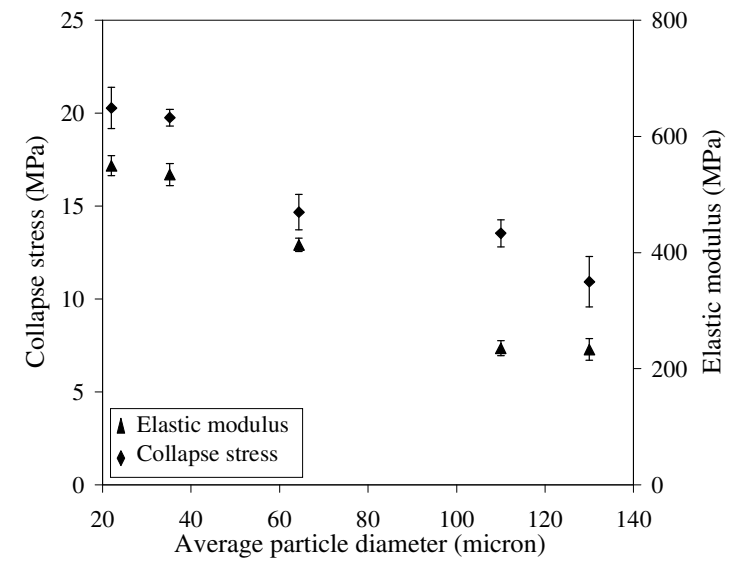

(b)

Figure 4. Variation of (a) porosity and permeability constant and (b) collapse stress and elastic modulus with respect to particle diameter of the PMMA beads.

\section{Summary}

The results clearly show that there is a strong correlation between pore morphology, water permeability and mechanical behavior of PMMA-based porous plastics. The macropore structure and pore connectivity is significantly affected by the PMMA-bead size distribution and relative concentration of the water/surfactant constituents of the emulsion. Therefore, processing parameters need to be optimized to obtain plastic moulds for high-pressure ceramic casting with high performance and service life.

\section{Acknowledgements}

The authors acknowledge the support from Ege Vitrifiye Sanitaryware Inc. of Turkey. The authors also wish to thank to Ercan Erdoğan of Ege Vitrifiye for his assistance.

\section{References}

[1] V. Mazzanti : Process Engineering DKG 79 (2002) No.1-2

[2] A. Dortmans, R.G. Nelissen, H. Fischer: Process Engineering DKG 79 (2002) No.1-2

[3] E.J. Pique, L.J.M.G. Dortmans, G. With: Mater Sci. and Eng. A335 (2002) 217-227

[4] R.J. Stokes, D.F. Evans: Fundamentals of Interfacial Engineering (Wiley-VCH, USA 1997) 


\section{Euro Ceramics VIII}

10.4028/www.scientific.net/KEM.264-268

Microstructure-Performance Relation in PMMA-Based Open-Cell Porous Materials for High Pressure Ceramic Sanitaryware Casting

10.4028/www.scientific.net/KEM.264-268.2235

\section{DOI References}

[1] V. Mazzanti : Process Engineering DKG 79 (2002) No.1-2 10.1002/1521-3870(200201)48:1<93::AID-MALQ93>3.3.CO;2-\#

[3] E.J. Pique, L.J.M.G. Dortmans, G. With: Mater Sci. and Eng. A335 (2002) 217-227 10.1016/S0921-5093(01)01929-3 